\title{
PENGARUH PENERAPAN GREEN RETROFIT TERHADAP LIFE CYCLE COST PADA BANGUNAN GEDUNG
}

\author{
Aulia Rahmawati ${ }^{* 1}$, Wisnumurti ${ }^{2}$, Agung Murti Nugroho ${ }^{3}$ \\ 1Mahasiswa, Program Magister, Teknik Sipil, Fakultas Teknik, Universitas Brawijaya \\ 2 Dosen, Jurusan Teknik Sipil, Fakultas Teknik, Universitas Brawijaya \\ 3 Dosen, Jurusan Arsitektur, Fakultas Teknik, Universitas Brawijaya \\ Korespondensi: aulia03@gmail.com
}

\begin{abstract}
This study aims to investigate one of the benefits of retrofitting an existing educational building in its relation to the building's life-cycle cost. Choosing educational building as a target of green retrofit project and as an object of study for its relevance as an important part of nationwide green project is considered timely, given the fact that there hasn't been any retrofit project in Indonesia that targets educational building despite its necessity to create sustainable environmental management of educational facilities. The improvement made to the building by the project was measured using GREENSHIP Existing Building (EB), which is thelegitimate standard of assessment for the level of energy efficiency and conservation of buildings in Indonesia. Having been retrofitted, the building was rated Silver based on GREENSHIP EB rating system, and it wasa substantial progress compared to its previously non-rated status. The project had resulted in $0.45 \%$ decrease ofthe building's total life-cycle cost. Furthermore, it was found that green retrofitting that was particularly oriented towards Energy Efficiency and Conservation, Water Conservation as well as Indoor Health and Comfort categories could cause greater life-cycle cost reduction than retrofitting that was undertaken for the whole categories prescribed in GREENSHIP EB.
\end{abstract}

Keywords : energy efficiency, green retrofit, GREENSHIP, life-cycle cost

\section{PENDAHULUAN}

Sebagian besar pemerintahan di seluruh dunia telah sepakat untuk melakukan pengurangan emisi gas rumah kaca (GRK) dan konsumsi energi dari sumber daya yang tak terbarukan, salah satunya melalui perwujudan bangunan hijau [1]. Faktanya, jumlah gedung yang dibangun di negara-negara berkembang tiap tahunnya hanya setara dengan $1,5-2 \%$ dari jumlah bangunan eksisting [2], oleh karena itu pembangunan bangunan hijau baru tidak signifikan terhadap kebutuhan pengurangan konsumsi energi dan emisi GRK. Green retrofit merupakan solusi yang lebih baik daripada menciptakan bangunan hijau baru. Hal tersebut telah dibuktikan oleh beberapa penelitian terdahulu yang menyebutkan bahwa green retrofit yang dilakukan terhadap bangunan komersil memiliki banyak manfaat dalam aspek ekonomi, lingkungan dan sosial [3], serta mampu menghemat biaya operasional dan pemeliharaan gedung sebesar 10-20\% [4].

Penelitian ini dilakukan untuk menyelidiki apakah green retrofit juga dapat diterapkan secara sukses pada bangunan non komersial di Indonesia. Obyek penelitian yang dipilih adalah bangunan pendidikan dimana di Indonesia tipe bangunan ini belum tersentuh sama sekali oleh metode green retrofit, padahal bangunan pendidikan sangat memerlukan kenyamanan ruang yang optimal demi tercipta kegiatan belajar mengajar yang kondusif. Standar penilaian bangunan hijau menggunakan rating tools yang dikeluarkan oleh GREENSHIP dari Green Building Council Indonesia (GBCI) dan sejumlah SNI yang terkait. 
Hasil penilaian menentukan sejauh mana green retrofit dapat diterapkan, untuk kemudian dilakukan analisa life cycle cost baik sebelum dan sesudah bangunan mengalami perbaikan. Tujuan penelitian ini adalah untuk mengetahui sejauh mana efisiensi biaya yang dapat dicapai melalui penerapan green retrofit pada bangunan eksisting.

\section{METODE PENELITIAN}

\subsection{Obyek Studi}

Penelitian ini dilakukan di wilayah Universitas Brawijaya, salah satu kampus terbaik di kota Malang, dengan gedung terpilih yaitu gedung Teknik Industri (TI) Fakultas Teknik. Gedung TI merupakan bangunan pendidikan yang di dalamnya terdiri dari beberapa ruang kantor, ruang kelas dan laboratorium. Luas total bangunan adalah sebesar 3306,21 $\mathrm{m}^{2}$ yang terbagi menjadi 7 lantai. Bangunan eksisting ini telah beroperasi selama lebih dari 5 tahun dan belum pernah dilakukan penilaian GREENSHIP sebelumnya.

\subsection{Green Retrofit}

Metode green retrofit yang diterapkan pada sebuah bangunan eksisting bersifat sebagian atau menyeluruh dengan tujuan untuk meningkatkan kinerja energi dan lingkungan, konservasi sumber daya air, dan meningkatkan kualitas dan kenyamanan ruang [5]. Perbaikan yang dilakukan mencakup kualitas dan kuantitas bangunan dan dilaksanakan dalam metode yang menguntungkan secara finansial bagi pemilik bangunan.

\subsubsection{GREENSHIP Existing Building-GBCI}

Green Building Council Indonesia, sebagai salah satu anggota dari World Green Building Council, memiliki sistem rating yang salah satunya bernama GREENSHIP Existing Building (EB). Sistem penilaian ini merupakan sarana untuk menilai peringkat sebuah bangunan hijau terhadap pencapaian konsep bangunan ramah lingkungan. $\mathrm{Di}$ dalam GREENSHIP EB terdapat beberapa kategori, kriteria dan tolok ukur yang memiliki nilai (poin) tertentu [6]. Nilai minimum 41 mendapat peringkat Bronze, 53 Silver, 66 Gold, dan 83 Platinum.

Penilaian pada kategori Appropriate Site Development (ASD) dilakukan pada beberapa aspek tepat guna lahan, yaitu Community Accessibility, Motor Vehicle Reduction Policy, Site Landscaping, Heat Island Effect, Storm
Tabel 1. Kategori, kriteria dan tolok ukur dalam GREENSHIP EB

\begin{tabular}{|c|c|c|c|c|}
\hline \multirow{2}{*}{ Kategori } & \multicolumn{3}{|c|}{ Jumlah Kriteria } & \multirow{2}{*}{$\begin{array}{l}\text { Jumlah } \\
\text { tolok ukur }\end{array}$} \\
\hline & Prasyarat & Kredit & Bonus & \\
\hline $\begin{array}{l}\text { Appropriate Site } \\
\text { Development }\end{array}$ & 2 & 7 & - & 26 \\
\hline Energy & & & & \\
\hline $\begin{array}{l}\text { Efficiency and } \\
\text { Conservation }\end{array}$ & 2 & 5 & 2 & 30 \\
\hline $\begin{array}{l}\text { Water } \\
\text { Conservation } \\
\text { Material }\end{array}$ & 1 & 7 & 1 & 15 \\
\hline $\begin{array}{l}\text { Resources and } \\
\text { Cycle }\end{array}$ & 3 & 5 & - & 17 \\
\hline $\begin{array}{l}\text { Indoor Health } \\
\text { and Comfort }\end{array}$ & 1 & 8 & - & 22 \\
\hline $\begin{array}{l}\text { Building } \\
\text { Enviromental } \\
\text { Management }\end{array}$ & 1 & 5 & - & 11 \\
\hline Jumlah & 10 & 41 & 3 & 121 \\
\hline
\end{tabular}

Water Management, Site Management, dan Building Neighbourhood. Sejauh mana tingkat konservasi dan efisiensi energi pada gedung dapat terlihat pada poin yang dapat dihasilkan pada kategori Energy Efficiency and Conservation (EEC) yang memiliki kriteria Optimized Efficiency Building Energy Performance, Testing, Re-commissioning or Retro-commissioning, System Energy Performance, Energy Monitoring and Control, Operation and Maintenance, On Site Renewable Energy, dan Less Energy Emission.

Tingkat konservasi sumber daya air dapat terlihat pada kategori Water Conservation (WC) yang terdiri dari 8 kriteria yaitu Water Sub-Metering, Water Monitoring Control, Fresh Water Efficiency, Water Quality, Recycled Water, Potable Water, Deep Well Reduction, dan Water Tap Efficiency. Kategori Material Resource and Cycle (MRC) terdiri dari 5 kriteria, yaitu Non ODS Usage, Material Purchasing Practice, Waste Management Practice, Hazardous Waste Management, dan Management of Used Good.

Aspek kenyamanan dan kesehatan dalam ruang terdapat pada kategori Indoor Health and Comfort (IHC) yang terdiri dari 9 kriteria, yaitu Outdoor Air Introduction, Environmental Tobacco Smoke Control, $\mathrm{CO} 2$ and $\mathrm{CO}$ Monitoring, Physical, Chemical and Biological Pollutants, Thermal Comfort, Visual Comfort, Acoustic Level, dan Building User Survey. 
Manajemen lingkungan binaan dapat terlihat pada kategori Building Environmental Management (BEM) yang terdiri dari 5 kriteria, yaitu Innovations, Design Intent and Owner's Project Requirement, Green Operational and Maintenance Team, Green Occupancy/Lease, dan Operation and Maintenance Training.

\subsubsection{Standard Acuan Penilaian \\ GREENSHIP EB}

Sebagai parameter penilaian digunakan beberapa Peraturan Pemerintah, maupun SNI yang berlaku di Indonesia. Pada kategori ASD, penilaian fasilitas pedestrian didasarkan pada Permen PU No. 30/PRT/M/2006, sedangkan kriteria vegetasi pada RTH pekarangan harus sesuai dengan Permen PU No. 5/PRT/M/2008.

Perhitungan konservasi energi pada kategori EEC didasarkan pada SNI 03-6197-2000. Kualitas air minum pada kategori WC diatur oleh Permenkes no.492. Kategori IHC menggunakan SNI 03-6572-2001 untuk menilai sistem ventilasi dan pengkondisian udara, SNI 03-6197-2000 untuk konservasi energi pada sistem pencahayaan dan SNI 03-6386-2000 untuk menilai kenyamanan suara dalam bangunan.

\subsection{Life Cylce Cost (LCC)}

Pentingnya mengetahui nilai LCC adalah untuk dapat mengambil keputusan biaya terkait evaluasi sebuah proyek yang melibatkan semua biaya yang muncul sejak tahap awal perencanaan hingga pembongkaran komponen [7].

Sebagai catatan, hasil perhitungan LCC bukan merupakan total estimasi biaya selama jangka waktu gedung beroperasi, melainkan sebuah solusi alternatif bangunan yang lebih hemat secara finansial [8].

Biaya-biaya yang akan dihitung terbagi ke dalam tiga kategori, yaitu Biaya Awal (initial cost), Biaya Operasional dan Pemeliharaan (operational and maintenance cost) dan Biaya Penggantian (Gambar 1). Secara garis besar, perhitungan LCC dapat dirumuskan sebagai berikut:

$$
L C C=I+O M+R e p l
$$

dimana I adalah biaya awal, OM adalah biaya operasional dan pemeliharaan, serta Repl adalah biaya penggantian.

Untuk mendapatkan present value dari komponen biaya operasional dan pemeliharaan dan biaya penggantian digunakan metode
Present Worth Method atau Metode Nilai Sekarang [9], dengan rumus sebagai berikut :

$$
\mathrm{PV}=F V \frac{1}{(1+r)^{n}}
$$

dimana FV adalah future value, $\mathrm{r}$ adalah rate of return dan $\mathrm{n}$ adalah number of periods.

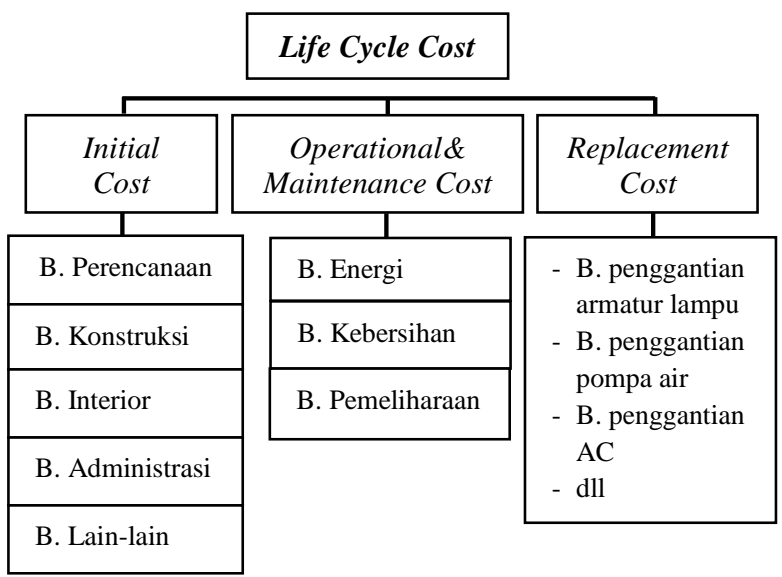

Gambar 1. Cost breakdown structure

\section{HASIL DAN PEMBAHASAN}

\subsection{Survey Lapangan}

Tahap awal penelitian adalah melakukan pengamatan dan pengukuran lapangan pada obyek terpilih, dengan acuan 6 kategori dalam GREENSHIP - GBCI. Total poin yang diperoleh pada kategori ASD adalah 10 poin, yaitu 3 poin dari kriteria Community Accessibility, 2 poin dari Site Landscaping, 2 poin dari Heat Island Effect, 1 poin dari Storm Water Management dan 2 poin dari Building Neighborhood.

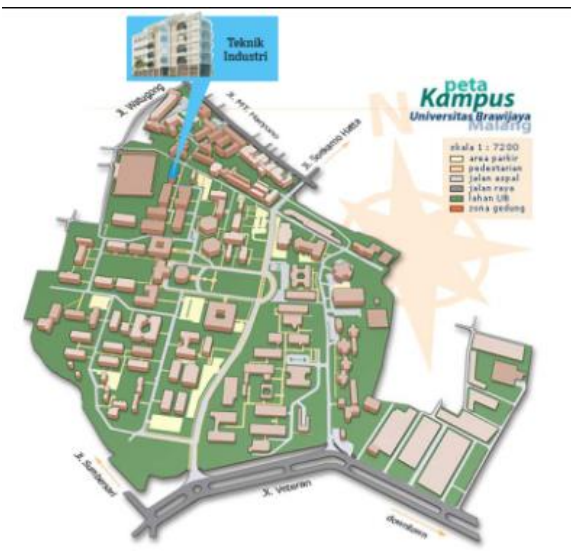

Gambar 2. Lokasi gedung TI 


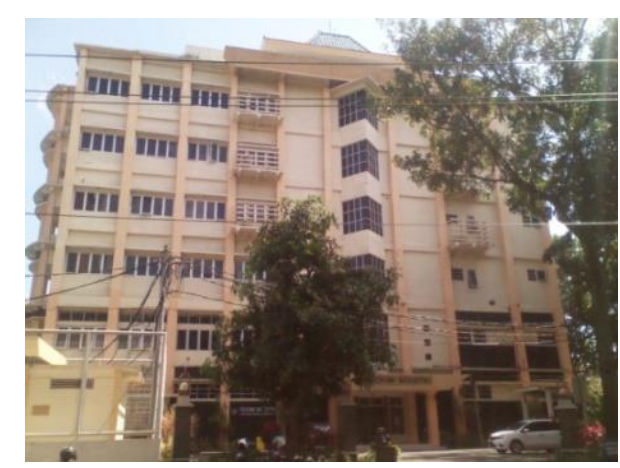

Gambar 3. Tampak gedung TI

Pada kategori EEC, kriteria Optimized Efficiency Building Energy Performance mendapat 9 poin karena IKE listrik berada di bawah standar acuan, sedangkan pada kriteria Testing, Recommisioning

or Retrocommisioning mendapat 1 poin. Pada kriteria System Energy Performance diperoleh 3 poin untuk penghematan konsumsi energi daya pencahayaan ruang serta penggunaan minimum $80 \%$ lampu LED pada ruang kerja, dan pada kriteria Energy Monitoring \& Control mendapat 1 poin dalam hal ketersediaan $\mathrm{kwH}$ meter untuk semua sistem dalam gedung.

Kategori Water Conservation hanya mendapat 1 poin pada kriteria Water Quality. Pada kategori Material Resource and Cycle poin yang diperoleh adalah 3 yaitu pada kriteria Non UDS Usage yang dibuktikan dengan penggunaan pendingin ruangan dan bahan pembersih gedung yang memiliki nilai ODP = 0.

Kategori IHC mengantongi 7 poin dari 5 kriteria. 2 poin diperoleh pada kriteria Outdoor Air Introduction, 1 poin untuk Thermal Comfort, 1 poin untuk Visual Comfort, 1 poin untuk Acoustic Level, , dan 2 poin untuk Building User Survey. Sedangkan pada kategori BEM poin yang diperoleh adalah 1 poin untuk kriteria Innovations dan 1 poin untuk kriteria Design Intent \& Owner's Project Requirement.

Dengan total poin 37, maka gedung TI belum mendapatkan predikat GREENSHIP.

\subsection{Retrofitting}

Penilaian awal GREENSHIP EB pada gedung TI menunjukkan bahwa bangunan tersebut belum dapat dikatakan bangunan hijau karena tidak mendapatkan predikat apapun. Mayoritas poin yang gagal didapatkan adalah pada kriteria kredit yang mensyaratkan adanya SOP atau komitmen manajemen gedung, selebihnya adalah kriteria terkait efisiensi energi baik listrik maupun air.

Rekomendasi green retrofit yang diusulkan untuk gedung ini memiliki target minimum 41 poin untuk dapat meraih peringkat Bronze atau 53 untuk peringkat Silver.

\section{Kategori ASD}

Pengurangan area parkir sepeda motor dapat diterapkan kepada para mahasiswa. Mereka dapat menggunakan area parkir Teknik yang tersedia pada sebelah timur gedung. Selain itu, dilakukan pula penambahan rack parkir sepeda sejumlah 2 unit dan diletakkan pada area parkir mobil sisi selatan. Pihak manajemen perlu juga untuk merumuskan SPO pengendalian hama penyakit tanaman. Poin tambahan yang diperoleh adalah 3 .

2. Kategori EEC

Rekomendasi utama adalah dengan melakukan optimalisasi penggunaan pencahayaan alami, yaitu dengan 2 cara : untuk ruang-ruang yang berada pada sisi timur gedung dan sering digunakan, gorden perlu dibuka secara penuh setiap ruang digunakan; penggantian 60 buah lampu selasar dan lobby dengan lampu sensor gerak.

Optimalisasi penghawaan alami juga perlu dilakukan pada ruang-ruang yang digunakan selama lebih dari 90 menit, dengan cara menyalakan pendingin ruangan ketika siang hari, selebihnya cukup dengan memanfaatkaan bukaan jendela. Efisiensi tersebut menyumbang 2 poin pada System Energy Performance.

Selain itu, didapatkan 2 poin untuk kriteria Energy Monitoring \& Control dan 3 poin pada Operation and Maintenance. Pada kategori ini diperoleh tambahan poin sebesar 7 poin.

Tabel 2. Total poin awal dan akhir

\begin{tabular}{lcc}
\hline \multicolumn{1}{c}{ Kategori } & $\begin{array}{c}\text { Poin } \\
\text { Awal }\end{array}$ & $\begin{array}{c}\text { Poin } \\
\text { Akhir }\end{array}$ \\
\hline $\begin{array}{l}\text { Appropriate Site Development } \\
\text { Energy Efficiency \& }\end{array}$ & 10 & 13 \\
Conservation & 14 & 21 \\
Water Conservation & & \\
Material Resources \& Cycle & 3 & 5 \\
Indoor Health \& Comfort & 7 & 10 \\
Building Enviromental & 2 & 7 \\
Management & & \\
\hline \multicolumn{1}{c}{ TOTAL } & $\mathbf{3 7}$ & $\mathbf{6 1}$ \\
\hline \multicolumn{1}{c}{ Predikat } & - & Silver \\
\hline \multicolumn{1}{c}{}
\end{tabular}


3. Kategori WC

Pemasangan water sub metering pada gedung, penambahan sistem air daur ulang yang berasal dari air limpasan hujan untuk kebutuhan flushing WC, pengadaan sistem filtrasi untuk air minum, serta penambahan fitur kran auto stop sebesar 50\% pada setiap area kamar mandi merupakan rekomendasi yang tepat dalam rangka konservasi air pada gedung. Poin tambahan adalah 4 .

4. Kategori MRC

Perlu dirumuskan SOP untuk kegiatan pemilahan sampah organik dan anorganik, serta penyaluran barang bekas. Poin tambahan yang diperoleh adalah 2 .

5. Kategori IHC

Larangan merokok perlu diterapkan melalui media tulis seperti sticker pada setiap dinding lobby atau poster yang ditempel pada majalah dinding. Pada ruang serbaguna lantai 6 perlu ditambahkan instalasi sensor gas $\mathrm{CO} 2$. Poin yang diperoleh adalah 3 .

6. Kategori BEM

Usaha perbaikan pada kategori WC dan MRC dapat menyumbang 2 poin untuk kriteria Innovations. Pada dasarnya, di dalam struktur manajemen gedung TI terdapat sejumlah sumber daya manusia yang memiliki kompetensi dalam hal penerapan prinsip-prinsip lingkungan berkelanjutan. Oleh karena itu, tambahan poin dapat diperoleh untuk kriteria Green Operational \& Maintenance Team dan Green Occupancy. Total poin tambahan untuk kategori ini adalah 5.

Dengan demikian, total poin yang diperoleh setelah diterapkan green retrofit pada bangunan eksisting adalah sebesar 61 dengan peringkat Silver. Perbandingan total poin awal dan akhir dapat dilihat pada tabel 2.

\subsection{Analisa Life Cycle Cost}

Informasi biaya awal diperoleh dari staff Barang Milik Negara di kantor Dekanat Fakultas Teknik, perhitungannya dapat dilihat pada tabel 3 .

Untuk biaya administrasi dan biaya lain-lain menggunakan perhitungan $5 \%$ dan 15\% dari biaya konstruksi [9]. Time value of money tidak mempengaruhi nilai biaya awal karena biaya tersebut terjadi hanya satu kali di awal saja.
Tabel 3. Perhitungan biaya awal

\begin{tabular}{lr}
\hline \multicolumn{1}{c}{ Uraian Biaya } & \multicolumn{1}{c}{ Estimasi Biaya (Rp) } \\
\hline Biaya Perencanaan & $301.990 .000,-$ \\
Biaya Konstruksi & $13.835 .495 .261,-$ \\
Biaya Interior & $163.000 .000,-$ \\
Biaya Adm (5\%) & $691.774 .764,-$ \\
Biaya Lain-lain $(15 \%)$ & $2.075 .324 .289,-$ \\
\hline Total Biaya Awal & $\mathbf{1 7 . 0 6 7 . 5 8 4 . 3 1 3 , -}$ \\
\hline
\end{tabular}

Sedangkan untuk biaya operasional dan pemeliharaan gedung serta biaya penggantian memerlukan perhitungan Present Worth Method, dimana ditentukan bahwa tingkat suku bunga (i) adalah 7,14\%, periode analisa (n) 10 tahun dimana tahun ke-0 adalah 2018 dan inflasi diabaikan. Nilai present worth (PV) dari semua biaya kemudian dijumlahkan bersama dengan biaya awal untuk mendapatkan total LCC dari bangunan eksisting.

Tabel 4. Perhitungan biaya awal setelah retrofit

\begin{tabular}{lr}
\multicolumn{1}{c}{ Uraian Biaya } & Estimasi Biaya (Rp) \\
\hline Biaya Perencanaan & $301.990 .000,-$ \\
Biaya Konstruksi & $13.835 .495 .261,-$ \\
Biaya Interior & $163.000 .000,-$ \\
Biaya Adm (5\%) & $691.774 .764,-$ \\
Biaya Lain-lain $(15 \%)$ & $2.075 .324 .289,-$ \\
Biaya rack sepeda & $2.800 .000,-$ \\
Biaya lampu sensor gerak & $4.500 .000,-$ \\
untuk selasar/lobby & \\
Biaya instalasi sistem daur & $20.000 .000,-$ \\
ulang air hujan & \\
Biaya kran air auto stop & $7.500 .000,-$ \\
Biaya pengelolaan limbah & $1.000 .000,-$ \\
Biaya instalasi sensor CO2 & $6.600 .000,-$ \\
Biaya tong sampah 3jenis & $\mathbf{1 7 . 1 2 7 . 0 8 4 . 3 1 3 , -}$ \\
\hline Total Biaya Awal &
\end{tabular}

Metode yang sama juga diterapkan untuk mendapatkan nilai LCC setelah penerapan green retrofit. Terdapat 2 alternatif perhitungan LCC yang diusulkan. Alternatif $A$ adalah perhitungan LCC dengan melibatkan seluruh biaya yang muncul akibat penerapan green retrofit. Alternatif B adalah perhitungan LCC dengan hanya memasukkan biaya yang berhubungan langsung dengan efisiensi energi, yaitu biaya lampu sensor, biaya instalasi sistem daur ulang air hujan dan biaya kran air auto stop. Perbandingan hasil analisa LCC bangunan eksisting dan bangunan retrofit dalam 2 alternatif dapat dilihat pada tabel 7 . 
Tabel 5. Perhitungan biaya operasional dan pemeliharaan

\begin{tabular}{lccrccc}
\hline & \multicolumn{3}{c}{ Estimasi Biaya (Rp) } & \multicolumn{3}{c}{ Present Worth (Rp) } \\
\cline { 2 - 7 } \multicolumn{1}{c}{ Uraian Biaya } & Eksisting & $\begin{array}{c}\text { Setelah } \\
\text { Retrofit (A) }\end{array}$ & $\begin{array}{c}\text { Setelah } \\
\text { Retrofit (B) }\end{array}$ & Eksisting & $\begin{array}{c}\text { Setelah } \\
\text { Retrofit (A) }\end{array}$ & $\begin{array}{c}\text { Setelah } \\
\text { Retrofit (B) }\end{array}$ \\
\hline $\begin{array}{c}\text { Biaya energi } \\
\text { - Biaya listrik }\end{array}$ & $82.944 .000,-$ & $66.786 .000,-$ & $66.636 .000,-$ & $610.475 .060,-$ & $491.550 .774,-$ & $490.446 .761,-$ \\
$-\begin{array}{l}\text { - Biaya air } \\
\text { Biaya kebersihan }\end{array}$ & $14.899 .000,-$ & $14.899 .000,-$ & $14.899 .000,-$ & $109.657 .937,-$ & $109.657 .937,-$ & $109.657 .937,-$ \\
Biaya perawatan & $20.000 .000,-$ & $20.000 .000,-$ & $20.000 .000,-$ & $147.201 .741,-$ & $147.201 .741,-$ & $147.201 .741,-$ \\
\hline \multicolumn{1}{c}{ Total Biaya Operasional dan Pemeliharaan } & & $\mathbf{8 6 7 . 3 3 4 . 7 3 8 , -}$ & $\mathbf{7 4 8 . 4 1 0 . 4 5 2 , -}$ & $\mathbf{7 4 7 . 3 0 6 . 4 3 9 , -}$ \\
\hline
\end{tabular}

Tabel 6. Perhitungan biaya penggantian

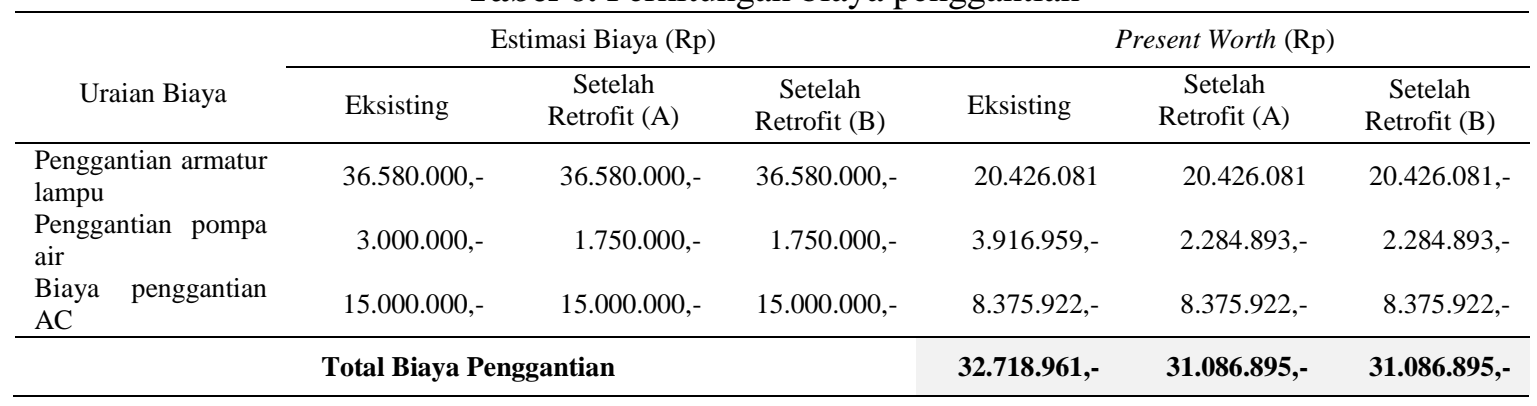

Tabel 7. Analisa life cycle cost

\begin{tabular}{lccc}
\hline \multirow{2}{*}{ Uraian } & \multicolumn{3}{c}{ Present Worth 10 years (Rp) } \\
\cline { 2 - 4 } Biaya & Eksisting & $\begin{array}{c}\text { Setelah Retrofit } \\
\text { (A) }\end{array}$ & $\begin{array}{c}\text { Setelah Retrofit } \\
(\mathrm{B})\end{array}$ \\
\hline Biaya awal & $17.067 .584 .314,-$ & $17.127 .084 .313,-$ & $17.109 .184 .313,-$ \\
Biaya OM & $867.334 .738,-$ & $784.410 .452,-$ & $747.306 .439,-$ \\
$\begin{array}{l}\text { Biaya } \\
\text { penggantian }\end{array}$ & $32.718 .961,-$ & $31.086 .895,-$ & $31.086 .895,-$ \\
\hline Total LCC & $\mathbf{1 7 . 9 6 7 . 6 3 8 . 0 1 3}$ & $\mathbf{1 7 . 9 0 6 . 5 8 1 . 6 6 0 , -}$ & $\mathbf{1 7 . 8 8 7 . 5 7 7 . 6 4 7 , -}$ \\
\hline
\end{tabular}

Penghematan pada komponen biaya operasional dan pemeliharaan pada alternatif A adalah sebesar Rp. 82.924.286,- $(9,56 \%)$, sedangkan pada alternatif B adalah sebesar Rp. 120.028.299,- $(13,84 \%)$. Sedangkan pada komponen biaya penggantian juga didapatkan penghematan biaya, yaitu sebesar $\mathrm{Rp}$. 1.632.066,- baik pada alternatif A maupun alternatif $\mathrm{B}$.

Dengan demikian, penghematan total LCC pada alternatif A adalah sebesar Rp. 61.056.353,- $(0,34 \%)$, sedangkan penghematan pada alternatif $\mathrm{B}$ adalah sebesar $\mathrm{Rp}$. $80.060 .366,-(0,45 \%)$.

\section{KESIMPULAN DAN SARAN \\ 4.1. Kesimpulan}

Penilaian GREENSHIP EB pada Gedung TI menyatakan bahwa bangunan eksisting tersebut belum mendapatkan predikat apapun. Setelah green retrofit diterapkan, baik secara kualitas maupun kuantitas, gedung TI dapat meraih predikat Silver. Disamping melakukan optimalisasi energi, kebijakan dan komitmen manajemen merupakan hal yang utama pula untuk dapat dipenuhi.

Penelitian ini merumuskan bahwa green retrofit yang didasarkan pada GREENSHIP EB dapat berpengaruh terhadap penghematan biaya operasional dan pemeliharaan serta biaya penggantian yang berdampak pada penghematan LCC bangunan. Penghematan biaya menjadi lebih besar apabila green retrofit difokuskan pada 3 (tiga) kategori, yaitu Energy Efficiency and Conservation; Water Conservation; dan Indoor Health Comfort dimana biaya operasional dan pemeliharaan dapat ditekan hingga $13,84 \%$ dan biaya penggantian sebesar 5\%, dengan penghematan total LCC adalah sebesar $0,45 \%$.

\subsection{Saran}

Untuk penelitian lebih lanjut hendaknya menggunakan obyek studi bangunan eksisting yang lebih membutuhkan green retrofit agar didapatkan penghematan LCC yang lebih besar. Selain itu, perlu juga ditambahkan acuan selain GREENSHIP EB dalam menerapkan green retrofit untuk dapat memperdalam analisa.

\section{DAFTAR PUSTAKA}

[1] Building and Construction Authority Singapore. (2010). Building Planning and Massing. Singapore : The Centre for Sustainable Buildings and Construction. 
[2] Bullen, P.A. (2007). Adaptive reuse and sustainability of commercial buildings. Facilities, Vol. 25, hal. 20-31.

[3] Vanadila, Veby. (2012). Green Building in Indonesia. Dipetik 26 April, 2017, dari Academia : https://www.academia.edu/

[4] YU, S.-M., TU, Y., \& Luo, C. (2011, Agustus). Green Retrofitting Costs and Benefits : A New Research Agenda. IRES Working Paper Series, hal. 1-15.

[5] USGBC. (2003). The Costs and Financial Benefits of Green Buildings : A Report to California's Sustainable Building Task Force. San Fransisco, CA : USGBC.

[6] Green Building Council Indonesia (2016). GREENSHIP Existing Building version 1.1.
Jakarta : Divisi Rating dan Teknologi Green Building Council Indonesia.

[7] Fuller, S. K. \& Peterson, S. R. (1995). Life cycle costing manual for the Federal energy management program. NIST Handbook 135.

[8] Junus, T.D., Fitria, D., \& Dimas, T.A. (2017, March 1). Pengambilan Keputusan Investasi dengan Menggunakan Metode Life Cycle Cost Analysis. Dipetik 16 Maret, 2018, dari PT Asdi Swasatya:

http://www.pt-asdi.com/article/detail/36

[9] Fabricky, W. J., and Benjamin S. Blanchard. (1991). Life Cycle Cost and Economic Analysis. Prentice-Hall, Inc. : Englewood Cliffs. 